\title{
Research on the Correlation Mechanism of Psychological Contract Violation and Physicians' Behaviour Options (EVLN) in Tertiary Public Hospitals: An Empirical Study in Beijing, China
}

\section{Lujia Hu}

Tianjin Hexi Center for Disease Control and Prevention

Junli Zhu ( $\nabla$ smallying@126.com )

Capital Medical University

Yao Zhang

Bejing Tongren Hospital

Yun Chen

Beijing Institute of Mental Health

Yufei Jia

Beijing Shijitan Hospital

\section{Research Article}

Keywords: tertiary public hospitals, physicians, psychological contract violation, EVLN, correlation mechanism

Posted Date: May 19th, 2021

DOI: https://doi.org/10.21203/rs.3.rs-506574/v1

License: (c) (i) This work is licensed under a Creative Commons Attribution 4.0 International License. Read Full License 


\title{
Research on the Correlation Mechanism of Psychological Contract Violation and Physicians' Behaviour Options (EVLN) in Tertiary Public Hospitals: an Empirical Study in Beijing, China
}

Lujia $\mathrm{Hu}^{1,2}$, Junli Zhu ${ }^{1 *}$, Yao Zhang ${ }^{3}$, Yun Chen ${ }^{4.5,6}$, Yufei Jia ${ }^{7}$

\footnotetext{
${ }^{1}$ School of Public Health, Capital Medical University, Beijing, China

2 Tianjin Hexi Center for Disease Control and Prevention, Tianjin, China

${ }^{3}$ Bejing Tongren Hospital, Capital Medical University, Beijing, China

4 The National Clinical Research Center for Mental Disorders \& Beijing Key Laboratory of Mental Disorders, Beijing Anding Hospital, Capital Medical University, Beijing, China

${ }^{5}$ Advanced Innovation Center for Human Brain Protection, Capital Medical University, Beijing, China

${ }^{6}$ Beijing Institute of Mental Health, Beijing, China

7 Beijing Shijitan Hospital, Capital Medical University, Beijing, China

* Correspondence: smallying@126.com (Junli Zhu)
}

\begin{abstract}
Background: With the continuous deepening of the new medical reform, the hospital management system has changed, and there have been corresponding changes at the organisational and individual levels. As the main body of medical services, how to effectively motivate physicians is an important issue for hospital management.
\end{abstract}

Purpose: the purpose of this research was to investigate the correlation mechanism between psychological contract violation and the EVLN behavior of physicians in tertiary 
public hospitals and explore new ideas for encouraging physicians, and provides governance and intervention strategies for management in hospitals.

Methodology: Based on related theories such as psychological contract, this research used the stratified cluster sampling method to survey a total of 321 physicians in four public hospitals in Beijing, established an Excel database, and used Stata15.0 to construct regression models to analyse the correlation mechanism between psychological contract violation and the EVLN behavior of physicians in tertiary public hospitals.

Findings: Psychological contract violation has a positive effect on exit behavior and neglect behavior, and a negative effect on voice behavior and loyalty behavior. Organisational justice has a mediating effect on the direct correlation mechanism models.

Practice Implications: Our results suggest that it is necessary to pay attention to the psychological contract violation of physicians, build a good psychological contract relationship between public hospitals and physicians, and make full use of the role of organisational justice to promote positive behaviors of physicians, and moreover to prevent and curb negative behaviors of physicians.

Keywords: tertiary public hospitals; physicians; psychological contract violation; EVLN; correlation mechanism 


\section{Introduction}

In China, public hospitals that absolutely dominate the market are positioned as public welfare institutions. In 2009, China started a new round of medical and health system reforms, including the establishment of a corporate governance structure, the adjustment of medical service prices, the improvement of basic medical security payment, a hierarchical diagnosis and treatment system, and the establishment of a modern hospital management system policy. These reforms changed the external environment, internal organisational structure, and operational management of the public hospital. In the face of rising medical service costs, continuous fee control measures by medical insurance departments and patient concerns regarding service quality, hospitals are facing unprecedented pressure. Physicians hold a centrally important function in hospitals, with a monopoly on decision-making with regard to admitting and discharging patients, selecting and performing clinical procedures, and prescribing pharmaceuticals. Thus, physicians are critical to a hospital's organisational success.

For a long time, Chinese medical staff have faced harsh professional environments, with long working hours, high pressure, insufficient labour value, and strained physician-patient relations, especially with the frequent occurrence of severe injuries. According to incomplete statistics, from July 2001 to July 2018, there were a total of 47 injury and medical cases resulting in the death of medical staff, which greatly affected the sense of security and practice confidence of medical staff. The 'Physician Occupation Satisfaction' survey conducted by the China Youth Daily Social Survey Centre and APP 'Physician Chunyu' on 467 medical workers showed that $39.6 \%$ of the interviewed 
physicians clearly expressed dissatisfaction with their work (2015)[1]. A 2015 survey that reported on the attrition of physicians disclosed that in the first, second, and third level hospitals, the percentages of physicians who had resigned were $45.4 \%, 58 \%$, and $63.4 \%$, respectively. The turnover of physicians not only causes an increase in human resources costs, but also affects the quality of medical care and further aggravates the relationship between physicians and patients. Many hospitals are confronted with a physician shortage. Some, especially young physicians, choose to give up their medical work and move to other industries, which is a huge loss for both individuals and society.

In response to these challenges, hospitals have attempted to improve the hospital-physician relationship. Previous literature used psychological contract theory to study the hospital-physician relationship and found that the fulfilment of the psychological contract can result in positive attitudinal and behavioural responses of physicians, such as job satisfaction and organisational citizenship behaviour (Bellou, 2009; Trybou, 2017)[2,3]. The violation of the psychological contract can result in negative attitudinal and behavioural responses of physicians, such as job dissatisfaction and thoughts of quitting (Bunderson,2001; Trybou, 2015)[4,5]. Different from the international mainstream model that physicians are free practitioners, in China, physicians are 'unit persons' and affiliated with medical institutions. As mentioned above, China's public medical institutions are public welfare institutions, and physicians affiliated with them are given the identity of an institution establishment worker, which is similar to a civil servant. These systems hinder the normal flow of Chinese physicians. Differences in Chinese and Western cultures maybe make Chinese physicians' behavioural choices in 
the case of psychological contract violation different. Only a few articles have studied the scale of Chinese physicians' psychological contract or the relationship between the psychological contract and job satisfaction, turnover intention, and passive loyalty (Zhang, M., et al, 2017; Wu, ZY., 2013; Zhou, P., 2019)[6-8]. Leineweber, C. et al. (2020)[9] found that group turnover were negatively with changes in interpersonal justice perceptions. Zhou, P. (2019)[8] explored the mechanism between physicians' psychological contract violations and their turnover willingness with the mediating effects of perception of organisational justice. Obviously, research into the behavioural choices of Chinese physicians is insufficient, especially since behaviours like suggestion and neglect have not been studied yet. This study summarises physicians' behavioural choices facing psychological contract violations under the framework of EVLN (Exit, Voice, Loyalty and Neglect) behaviour. Based on the theory of psychological contract violation, this study included physicians in public hospitals in Beijing as the research object to study the mechanism between physicians' psychological contract violation and different behaviour choices, aiming to better understand the psychological and behavioural changes of physicians in public hospitals under the background of organisational change, and create a better hospital-physician relationship.

\section{Theoretical background}

\subsection{Psychological contract violation (PCV)}

The psychological contract refers to 'individual beliefs, shaped by the organisation, regarding terms of an exchange agreement between individual and organisation (Rousseau, 1995)[10]. Schein (1980)[11] pointed out that the 'self-evident' contract that 
exists in people's minds, although it is not stated, is a powerful determinant that affects employees' attitudes and behaviours toward the organisation. A violation of the psychological contract occurs when an employee perceives that the organisation has failed to fulfil one or more of its obligations comprising the psychological contract (Rousseau \& Parks, 1993)[12]. Previous researchers conclude that psychological contract violation may occur when the organisation violates on purpose or due to unforeseen reasons, and it may also occur when employees' understanding of organisational commitments is inconsistent with that of the organisation (Rousseau, 1995; Morrison \& Robinson, 1997; Turnley \& Feldman, 1999a)[10,13,14]. Scholars' understanding of psychological contracts is divided into 'narrow view' and 'broad view'. The broad view emphasises that psychological contracts should be discussed from the perspective of both employees and organisations. In the narrow sense, the analyses are only from the perspective of employees. This paper will study the response of physicians in Chinese public hospitals to a psychological contract violation based on the narrow view. Previous research mainly divided the psychological contract into two-dimensional and three-dimensional aspects (Roussean, 1990; Robinson et al., 1994; Robinson \& Morrison, 1997; Millward, 1998; Lee \& Tinsley, 1999; Shaprio \& Kessle, 2000)[15-20]. There is no unanimous conclusion regarding the discussion of psychological contract dimensions. Due to different employment conditions, the dimensions and specific content of the psychological contract will also be different. This research suggests that the psychological contract can express its meaning regardless of dimensions.

\subsection{EVLN behaviour}


Hirschman (1970)[21] summarised the employee's response to job dissatisfaction into the 'EVL' model: exit behaviour (Exit), advocacy behaviour (Voice), and loyal behaviour (Loyalty). Farrell (1983)[22] added neglect behaviour to the model to form the EVLN theoretical model, which was later extended by many other scholars. 'Exit' is the tendency and behaviour of employees to leave the organisation through resignation, transfer, or finding a new job within the organisation. 'Voice' refers to the behaviour of employees to improve their environment and conditions through active efforts such as discussing work difficulties with their supervisors or colleagues, proposing solutions, taking actions to solve the difficulties, and even seeking outside help. 'Loyalty' refers to the behaviour of employees to passively but optimistically wait for improvement of the environment and conditions by giving the organisation public and private support and acting as a well-behaved citizen. 'Neglect' refers to the behaviour of employees temporarily abandoning work by reducing effort, being late or absent for a long time, doing private tasks during working hours, and increasing the error rate. According to the active-passive dimensions, 'Exit' and 'Voice' are active responses, whereas 'Neglect' and 'Loyalty' are passive responses. According to the destructive-constructive dimensions, 'Exit' and 'Neglect' are destructive behaviours, while 'Voice' and 'Loyalty' are constructive behaviour (Farrell, 1983)[22]. Later scholars divided voice behaviour into aggressive voice and considerate voice (Hagedoorn \& Buunk, 1998; VanDyne, 1998; Hagedoorn et al, 1999; Liljegren, 2008)[23-26]. In this study, the considerate voice is used for the study of physician voice behaviour based on the EVLN model of Farrell (1983)[22] 


\subsection{Organisational justice as a mediator}

Organisational justice refers to the perceptions of fairness in organisational decision-making and resource allocation (Greenberg, 1987)[27]. Research on organisational justice began with Adams (1965)[28]. His research focused on the 'results' of distribution and put forward the concept of distributive justice (DJ). Thibaut \& Walker (1975)[29] attached importance to the distribution procedure before the distribution result, and proposed the concept of procedural justice (PJ). Then, Bies \& Moag (1986)[30] proposed the concept of interactive justice, which refers to the impact of the performer's attitudes and methods on employees' perception of fairness. Greenberg (1990)[31] divides interactive justice into interpersonal justice and informational justice. This study mainly focuses on the two most basic dimensions of procedural fairness and distribution fairness. Previous studies have found that organisational justice can strongly influence the relationship between psychological contract violation and employee response (Turnley \& Feldma, 1999a; Wei, F., 2004; Zhou, P., 2019)[14,32,8].

\section{Study framework}

EVLN theory provides a framework for employees' responses to psychological contract violation. As shown in Figure 1, physicians will respond to psychological contract violation by increasing turnover and negligence, as well as reducing their voice and loyalty; psychological contract fulfilment will increase physicians' positive behaviours because their needs are met to a greater degree. The greater the contract violation or imbalance, the greater the possibility of employees' anti-production or withdrawal behaviour (Chatman, 1991; Griffeth et al, 2000)[33,34]. Thus, this paper 
proposes the following hypotheses:

Hypothesis1 Psychological contract violation is significantly related to physicians' EVLN behaviours.

Hypothesis 1a Psychological contract violation is negatively related to physicians' constructive behaviours in public hospitals, including 'voice' and 'loyalty' behaviours.

Hypothesis $1 \mathrm{~b}$ Psychological contract violation is positively related to physicians' destructive behaviours, including 'exit' and 'neglect' behaviours.

In Figure 1, organisational justice plays a mediating effect on the relationship between psychological contract violation and physician's behaviours. Once physicians perceive a violation of the psychological contract, they may feel unfairly treated and dissatisfied, thereby affecting their behaviour choices. The previous literature has demonstrated that physicians have higher job satisfaction, less turnover intention, more affective organisational commitment, and are more motivated to contribute to the mission statement when they perceive a high level of fulfilment of the psychological contract and organisational justice (Bunderson, 2001; Trybou, 2016, 2017)[4,35,3]. Thus, this paper proposes the following hypotheses:

Hypothesis 2 Organisational justice plays an intermediary role between physicians' psychological contract violation and EVLN behaviour.

Hypothesis 2a Psychological contract violation is negatively related to organisational justice.

Hypothesis $2 \mathrm{~b}$ Organisational justice is significantly related to physicians' EVLN behaviour. 


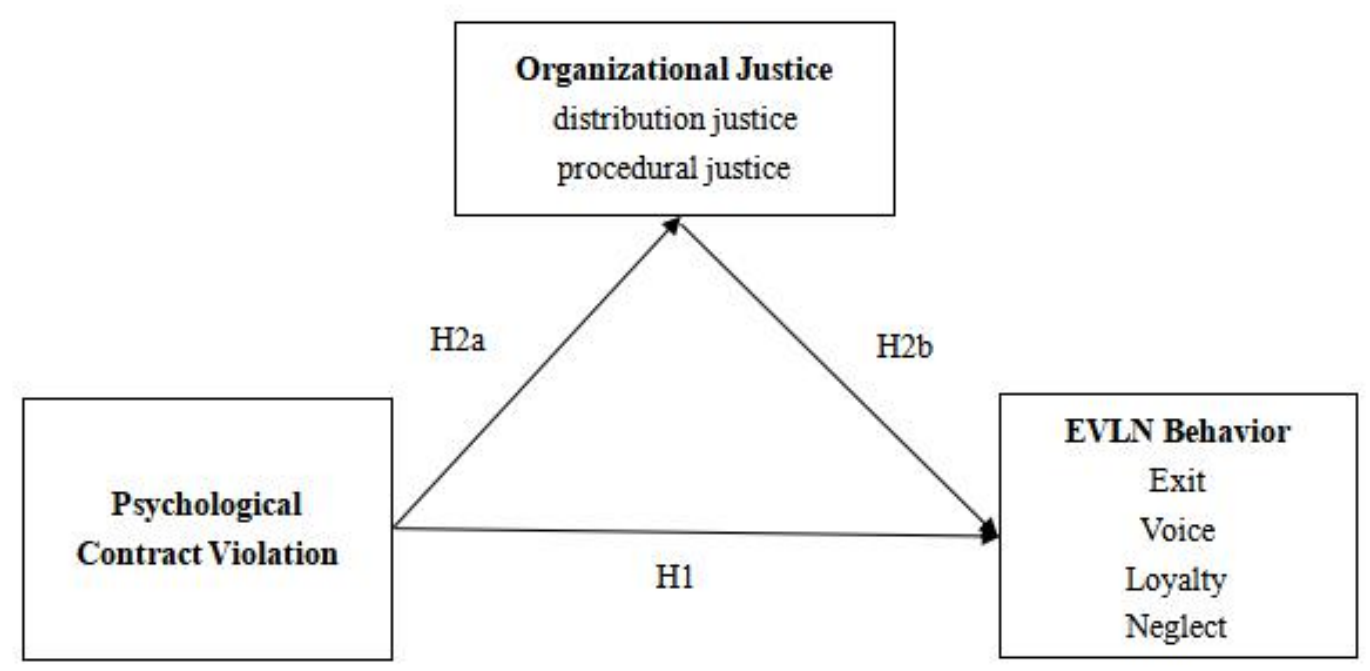

Figure 1. Study Framework.

\section{Methods}

\subsection{Sample and data}

In China, large public hospitals mainly refer to tertiary-A public hospitals. This study collected data from physicians at four top public hospitals in Beijing, including two general public hospitals and two specialised public hospitals, using questionnaire-based surveys. The tertiary first-class public hospitals of Beijing are mainly concentrated in the Dongcheng District, Xicheng District, Haidian District, Fengtai District, and Chaoyang District. We first randomly selected three urban areas (Dongcheng District, Xicheng District, and Haidian District) from them. Then, considering factors such as the number of tertiary hospitals in each district, two public hospitals were randomly selected from Xicheng District and one each from Dongcheng District and Haidian District. Finally, the study used proportional sampling to draw samples from official clinicians in sample hospitals based on scale. Participation in the study was voluntary and anonymous and a total of 321 physicians were assessed. After deleting respondents with less than one year 
of work, those in management positions, and questionnaires with missing values, the final sample consisted of 292 physicians.

\subsection{Instruments}

To satisfy the content validity, the instruments in this study were modified from the relevant literature that have shown sound levels of reliability and construct validity. Several steps were used to select items for the questionnaire. First, we translated the items from the existing English instruments into Chinese. Second, expert consultation including two professors and three hospital human resource managers provided assistance in scrutinising the appropriateness of the Chinese version of the questionnaire. Third, a small sample presurvey was executed for modifying the instrument. A five-point Likert was used, ranging from 5 for 'highly agree' to 1 for 'highly disagree'; exploratory factor analysis was used to extract the initial solution. As a rule of thumb, items that loaded less than 0.5 on their own factor or more than 0.3 on other factors were removed from the analysis (Hair et al., 2010)[36].

\subsubsection{Measure of psychological contract violation}

The construct of physician psychological contract violation was developed from Russeau (1990)[15] and Turnley \& Feldman (1999a) [14], including 12 items. Examples of items are 'The hospital pays salaries and bonuses based on your performance', 'The hospital provides you with opportunities for professional learning and technical training', and 'The hospital maintains a harmonious relationship between colleagues'.

\subsubsection{Measures of exit, voice, loyalty and neglect}

The construct of exit, voice, loyalty and neglect was developed by Rusbult et al. 
(1988)[37] and includes 18 items. According to the results of the exploratory factor analysis, three items were omitted and 15 items were finally retained. Exit assesses physicians' current job search behaviour; a sample item is: 'I will quit my current job'. Neglect assesses physicians' failure to meet basic in-role responsibilities and avoidance of extra-role assignments; a sample item is: 'I am occasionally late because I don't feel like going to work'. Voice assesses physicians' behaviour to find problems, solve problems, and improve the working environment; a sample item is: 'I frequently discuss work problems with my leader'. Loyalty assesses physicians' behaviour in terms of defending the hospital against outside threats and contributing to its good reputation among outsiders; a sample item is: 'In front of my friends, I always speak highly of my hospital'. The cumulative explanatory variance of the four factors was $70.24 \%$. The exit dimension includes four items, voice includes three items, loyalty includes four items and neglect dimension includes four items.

\subsubsection{Measures of organisational justice}

Organisational justice was compiled using the organisational justice scale of Colquitt (2001)[38]. Examples of items are: 'The allocation of the hospital is open and transparent' and 'My salary reflects my contribution'. The cumulative explained variance was $79.55 \%$ and procedural justice and distributive justice each had six items.

\subsection{Analysis}

This study used Stata 15.0 for descriptive statistics analysis, exploratory factor analysis, and regression modelling. Cronbach's alphas and coefficients were used to assess the reliability and validity of the scales. The Sobel test (1982)[39] was used to 
explore the mediating effect of organisational justice between psychological contract violation and EVLN behaviour. The relationship between the variables was: (1) EVLN = $\beta_{11}$ PCV $+\beta_{10} ;$ (2) Justice $=\beta_{21}$ PCV $+\beta_{20} ;$ (3) EVLN $=\beta_{31} P C V+\beta_{32}$ Justice $+\beta_{30}$. A significant mediating effect must satisfy: 1 . The independent variable in equations (1) and (2) can predict the dependent variable and the intermediate variable, $\beta 11$ and $\beta 21$ are significant; 2. The intermediate variable in equation (3) can predict the dependent variable, and $\beta 32$ is significant; 3. After the intermediate variable is introduced in equation (3), the influence of the independent variable on the dependent variable must be weakened or eliminated, $\beta 31<\beta 11$ (partial mediation) or $\beta 31$ is not significant (complete mediation).

\section{Data analysis and results}

\subsection{Descriptive statistics analysis}

In total, 292 valid questionnaires were collected. Among the respondents, 107 (36.60\%) were male and $185(63.40 \%)$ were female; $230(78.80 \%)$ of the respondents were married. In terms of age, $3.80 \%$ of respondents were aged $\leq 25$ years, $40.40 \%$ were $26-35$, $38.70 \%$ were $36-45$ years, $16.80 \%$ were $46-55$ years, $0.30 \%$ were 56 above years. Respondents with a Master's degree or above accounted for $84.30 \%$. Physicians from general hospitals accounted for $71.92 \%$ and those from specialist hospitals accounted for 28.08\%. Physicians of key disciplines comprised 51.00\%, while physicians of non-key discipline comprised $49.00 \%$. As for working years, $30.50 \%$ of respondents had worked $\leq 5$ years, $25.70 \%$ had worked $6-10$ years, $14.70 \%$ had worked $11-15$ years, and $29.10 \%$ had worked 16 years and above. Respondents who were chief physicians accounted for $7.20 \%$, deputy chief physicians were $27.70 \%, 33.90 \%$ were attending physicians, and physicians 
or below comprised $31.20 \%$.

\subsection{Reliability and validity analysis}

For composite reliability, the recommended value should exceed 0.7 (Hair et al., 2010)[35]. The results reveal that the composite reliability of each construct reached 0.7. Hence, the constructs had the desired reliability (Table 1, 2).

The establishment of content validity is to ensure that the scale contains appropriate and representative items that can measure the concept (Haynes, Richard \& Kubany, 1995)[40], generally using qualitative methods. In this study, the measures of constructs in this study were mainly based on domestic and foreign studies, and were modified for use. Thus, the measures used comply with standards of content validity and, hence, this study has content validity.

This study used exploratory factor analysis (EFA) to test convergent validity, which applied factor loading with a value exceeding 0.5 as the evaluation standard. If the factor loading for a measure fails to reach this value, this measure was not representative and was removed (Holden R J., 2010)[41]; otherwise, it was retained since its value exceeded the standard. This study applied the measurement model to verify the factor loading of various measures. The factor loading for construct measures must exceed 0.5 in order to be retained.

The results show that the standardised factor loadings were all higher than 0.5 and complied with suggestions by Hair et al. (2010)[36]. Additionally, Tables 2and 3 show that the standardised factor loadings, composite reliability, and AVE (Average Variance Extracted) were all higher than the values suggested by Fornell \& Larcker (2010)[42]. 
Thus, all constructs showed good convergent validity.

Table 1. Factor loadings, reliability and convergent validity of EVLN behavior.

\begin{tabular}{|c|c|c|c|c|c|c|}
\hline \multirow[b]{2}{*}{ Items } & \multirow[b]{2}{*}{ Neglect } & \multirow[b]{2}{*}{ Loyalty } & \multirow[b]{2}{*}{ Exit } & \multicolumn{3}{|c|}{ Composite } \\
\hline & & & & Voice & reliability & AVE \\
\hline Ex1 & .265 & -.090 & .842 & -.147 & 0.865 & 0.780 \\
\hline Ex2 & .110 & -.272 & .785 & .119 & & \\
\hline Ex3 & .538 & -.140 & .669 & .032 & & \\
\hline Ex4 & .565 & -.094 & .655 & -.060 & & \\
\hline Ne1 & .789 & -.123 & .296 & -.096 & 0.886 & 0.751 \\
\hline $\mathrm{Ne} 2$ & .815 & -.041 & .175 & .100 & & \\
\hline $\mathrm{Ne} 3$ & .761 & -.070 & .149 & -.011 & & \\
\hline $\mathrm{Ne} 4$ & .798 & -.124 & .120 & -.102 & & \\
\hline Vo1 & -.164 & .183 & .099 & .791 & 0.792 & 0.730 \\
\hline Vo2 & -.045 & .284 & -.007 & .837 & & \\
\hline Vo3 & .154 & .166 & -.130 & .810 & & \\
\hline Lo1 & -.153 & .820 & -.059 & .133 & 0.842 & 0.756 \\
\hline Lo2 & -.326 & .690 & .000 & .390 & & \\
\hline Lo3 & -.094 & .802 & -.218 & .231 & & \\
\hline Lo4 & .058 & .761 & -.239 & .159 & & \\
\hline
\end{tabular}

Table 2. Factor loadings, reliability and convergent validity of organizational justice.

\begin{tabular}{llll}
\hline & \multicolumn{2}{c}{ Distribution } & Composite \\
Items & Procedural justice & AVE \\
& justice & reliability & \\
\hline
\end{tabular}




\begin{tabular}{lllll}
\hline$j 1$ & 0.368 & $\mathbf{0 . 7 3 1}$ & 0.940 & 0.731 \\
$\mathrm{j} 2$ & 0.352 & $\mathbf{0 . 8 6 1}$ & \\
$\mathrm{j} 3$ & 0.394 & $\mathbf{0 . 7 8 1}$ & \\
$\mathrm{j} 4$ & 0.293 & $\mathbf{0 . 8 2 0}$ & \\
$\mathrm{j} 5$ & $\mathbf{0 . 8 1 6}$ & \\
$\mathrm{j} 6$ & 0.390 & $\mathbf{0 . 7 3 7}$ & \\
$\mathrm{j} 7$ & 0.490 & 0.454 & \\
$\mathrm{j} 8$ & $\mathbf{0 . 6 8 3}$ & 0.465 & \\
$\mathrm{j} 9$ & $\mathbf{0 . 7 7 1}$ & 0.316 & \\
$\mathrm{j} 10$ & $\mathbf{0 . 8 2 5}$ & 0.333 & \\
$\mathrm{j} 11$ & $\mathbf{0 . 8 5 5}$ & 0.407 & \\
\hline & $\mathbf{0 . 8 7 2}$ & 0.378 & \\
\hline
\end{tabular}

5.3. Direct effects of psychological contract violation

As shown in Table 3, the results show that there is a significant relationship between psychological contract violations and physician's EVLN behaviour. Psychological contract violation is positively correlated with exit behaviour $(\mathrm{r}=0.295, \mathrm{P}<0.05)$ and neglect behaviour $(\mathrm{r}=0.127, \mathrm{P}<0.1)$, and negatively correlated with voice behaviour $(\mathrm{r}=-0.246, \mathrm{P}<0.05)$ and loyalty behaviour $(\mathrm{r}=-0.466, \mathrm{P}<0.05)$, which means physicians who experience higher levels of psychological contract violation are more inclined toward job burnout or even leaving the organisation, show less enthusiasm for changing the working environment, and lower emotional dependence on the hospital.

Table 3. Descriptive statistics, correlations ( $n=292)$. 


\begin{tabular}{|c|c|c|c|c|c|c|c|c|c|c|}
\hline $\mathbf{r}$ & $\mathbf{M}$ & SD & 1 & 2 & 3 & 4 & 5 & 6 & 7 & 8 \\
\hline 1.PCV & 3.098 & 0.737 & & & & & & & & \\
\hline 2.Exit & 2.360 & 0.862 & $0.295^{* *}$ & & & & & & & \\
\hline 3.Neglect & 1.894 & 0.832 & $0.127^{*}$ & $0.623^{* *}$ & & & & & & \\
\hline 4.Voice & 3.182 & 0.749 & $-0.246^{* *}$ & -0.022 & -0.041 & & & & & \\
\hline 5.Loyalty & 3.403 & 0.835 & $-0.466^{* *}$ & $-0.376^{* *}$ & $-0.315^{* *}$ & $0.504^{* *}$ & & & & \\
\hline 6.EVLN & 2.710 & 0.444 & $-0.120^{*}$ & $0.591^{* *}$ & $0.604^{* *}$ & $0.629^{* *}$ & $0.352^{* *}$ & & & \\
\hline 7.PJ & 3.130 & 0.907 & $-0.504^{* *}$ & $-0.335^{* *}$ & $-0.174^{* *}$ & $0.242^{* *}$ & $0.426^{* *}$ & 0.058 & & \\
\hline 8.DJ & 3.057 & 0.954 & $-0.505^{* *}$ & $-0.399^{* *}$ & $-0.187^{* *}$ & $0.210^{* *}$ & $0.445^{* *}$ & 0.017 & $0.780^{* *}$ & \\
\hline 9.Justice & 3.093 & 0.878 & $-0.535^{* *}$ & $-0.390^{* *}$ & $-0.191^{* *}$ & $0.240^{* *}$ & $0.462^{* *}$ & 0.039 & $0.940^{* *}$ & $0.946^{* *}$ \\
\hline
\end{tabular}

PCV psychological contract violation; DJ distribution justice; PJ procedural justice

*. P-value <0.1;**. P-value $<0.05 ;{ }^{* * *}$. P-value $<0.001$

\subsection{Mediating the effects of organisational justice}

The variance inflation factor (VIF) for each variable was not greater than five, so the multi-collinearity was within the traditionally acceptable level. In Tables 4 and 5, the results of model (1) show that psychological contract violation is significantly positively correlated with exit and neglect behaviours $(\mathrm{P}<0.05)$, and is significantly negatively correlated with voice and loyalty behaviours; thus, hypotheses H1a and H1b are accurate. Model (2) shows that psychological contract violation is significantly negatively correlated with organisational justice. When procedural and distribution justice are added on the basis of Model (1), the influence of physicians' psychological contract violation on EVLN behaviour changes. Model (3) shows that, for negative behaviours, 
the regression coefficient of psychological contract violation on exit behaviour decreases $(\mathrm{P}<0.05)$, but the regression coefficient of neglect behaviour is not significant, indicating that organisational justice plays a partial mediating role between psychological contract violation and exit behaviour, and a complete mediating role between psychological contract violation and neglect behaviour. For positive behaviours, the absolute value of the regression coefficients of psychological contract violations on voice and loyalty behaviours decreased $(\mathrm{P}<0.05)$, indicating that organisational justice plays a part of the mediating role. Hypothesis $\mathrm{H} 2$ was supported. Table 6 shows that the mediating role of organisational justice accounts for more than $22 \%$ of the total effect. It clearly suggests that the transmission mechanism between physicians' psychological contract violations and EVLN behaviours, when physicians' psychological contract violation occurs, is mainly through the perception of organisational justice to change their behaviour choices.

Table 4. Mediating regression of procedural justice.

(1)

(2)

(3)

\begin{tabular}{lccccccccc} 
Variables & Exit & Neglect & Voice & Loyalty & PJ & Exit & Neglect & Voice & Loyalty4 \\
\cline { 2 - 9 } PCV & $0.342^{* * *}$ & $0.135^{* *}$ & $-0.253^{* * *}$ & $-0.518^{* * *}$ & $-0.606^{* * *}$ & $0.195^{* *}$ & 0.053 & $-0.172^{* *}$ & $-0.385^{* * *}$ \\
PJ & & & & & & & & & \\
& & & & & & $-0.242^{* * *}$ & $-0.125^{* *}$ & $0.134^{* *}$ & $0.218^{* * *}$ \\
Gender & -0.126 & $-0.183^{*}$ & 0.124 & 0.328 & $0.195^{* *}$ & -0.079 & -0.157 & 0.098 & 0.285 \\
Age & -0.048 & -0.077 & -0.025 & 0.140 & 0.146 & -0.013 & -0.057 & -0.044 & 0.108 \\
Working years & -0.043 & -0.042 & 0.077 & 0.005 & $-0.172^{* *}$ & -0.084 & -0.065 & 0.100 & 0.043 \\
Professional & -0.080 & -0.150 & 0.033 & 0.076 & -0.122 & -0.110 & $-0.167^{*}$ & 0.049 & 0.103
\end{tabular}


title

$\begin{array}{llllllllll}\text { Constant } & 1.973 & 2.520 & 3.547 & 3.860 & 5.065 & 3.197 & 3.202 & 2.867 & 2.754 \\ \text { F } & 6.010^{* * *} & 2.290^{* *} & 4.390^{* * *} & 20.13^{* * *} & 22.470^{* * *} & 7.820^{* * *} & 2.710^{* *} & 4.710^{* * *} & 20.42^{* * *} \\ \text { R2 } & 0.095 & 0.039 & 0.071 & 0.260 & 0.282 & 0.141 & 0.054 & 0.090 & 0.300\end{array}$

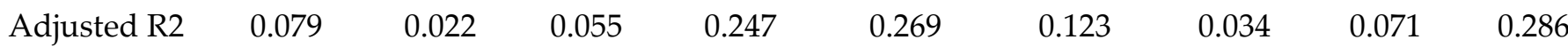

*. P-value <0.1;**. P-value <0.05;***. P-value $<0.001$

Table 5. Mediating regression of distribution justice.

\begin{tabular}{|c|c|c|c|c|c|c|c|c|c|}
\hline \multirow{2}{*}{ Variables } & \multicolumn{4}{|c|}{ (1) } & \multicolumn{2}{|l|}{ (2) } & \multicolumn{2}{|c|}{ (3) } & \multirow[b]{2}{*}{ Loyalty 4} \\
\hline & Exit & Neglect & Voice & Loyalty & DJ & Exit & Neglect & Voice & \\
\hline PCV & $0.342^{* * *}$ & $0.135^{* *}$ & $-0.253^{* * *}$ & $-0.518^{* * *}$ & $-0.637^{* * *}$ & $0.147^{* *}$ & 0.052 & $-0.196^{* *}$ & $-0.375^{* * *}$ \\
\hline DJ & & & & & & $-0.306^{* * *}$ & $-0.130^{* *}$ & $0.089^{*}$ & $0.223^{* * *}$ \\
\hline Gender & -0.126 & $-0.183^{*}$ & 0.124 & 0.328 & $0.285^{* *}$ & -0.039 & -0.146 & 0.098 & $0.264^{* *}$ \\
\hline Age & -0.048 & -0.077 & -0.025 & 0.140 & 0.095 & -0.019 & -0.064 & -0.033 & 0.119 \\
\hline Working years & -0.043 & -0.042 & 0.077 & 0.005 & -0.115 & -0.078 & -0.057 & 0.088 & 0.031 \\
\hline Professional & -0.080 & -0.150 & 0.033 & 0.076 & -0.023 & -0.088 & -0.153 & 0.035 & 0.082 \\
\hline \multicolumn{10}{|l|}{ title } \\
\hline Constant & 1.973 & 2.520 & 3.547 & 3.860 & 4.653 & 3.397 & 3.125 & 3.132 & 2.822 \\
\hline $\mathrm{F}$ & $6.010^{* * *}$ & $2.290^{* *}$ & $4.390^{* * *}$ & $20.13^{* * *}$ & $22.76^{* * *}$ & $10.220^{* * *}$ & $2.730^{* *}$ & $4.160^{* * *}$ & $21.01^{* * *}$ \\
\hline R2 & 0.095 & 0.039 & 0.071 & 0.260 & 0.285 & 0.177 & 0.054 & 0.081 & 0.307 \\
\hline Adjusted R2 & 0.079 & 0.022 & 0.055 & 0.247 & 0.272 & 0.160 & 0.035 & 0.061 & 0.292 \\
\hline
\end{tabular}

*. P-value $<0.1 ; * *$. P-value $<0.05 ; * *$. P-value $<0.001$

Table 6. Results of sobel test. 


\begin{tabular}{|c|c|c|c|c|c|c|c|c|}
\hline \multirow{2}{*}{ Items } & \multicolumn{4}{|c|}{ PJ } & \multicolumn{4}{|c|}{ DJ } \\
\hline & Exit & Neglect & Voice & Loyalty & Exit & Neglect & Voice & Loyalty \\
\hline \multicolumn{9}{|l|}{ Sobel test } \\
\hline $\mathrm{Z}$ & 3.640 & 2.109 & -2.363 & -3.745 & 4.678 & 2.138 & -1.667 & -3.987 \\
\hline $\mathrm{P}$ & $<0.001$ & 0.035 & 0.018 & $<0.001$ & $2.898 \mathrm{e}-06$ & 0.033 & 0.095 & $<0.001$ \\
\hline a coefficient & -0.606 & -0.606 & -0.606 & -0.606 & -0.637 & -0.637 & -0.637 & -0.637 \\
\hline b coefficient & -0.242 & -0.134 & 0.134 & 0.218 & -0.306 & -0.130 & 0.089 & 0.223 \\
\hline \multicolumn{9}{|l|}{ Indirect } \\
\hline & \multicolumn{7}{|c|}{ effect } & -0.142 \\
\hline Direct effect & 0.195 & 0.053 & -0.172 & -0.385 & 0.147 & 0.052 & -0.196 & -0.376 \\
\hline Total effect & 0.342 & 0.135 & -0.253 & -0.518 & 0.342 & 0.134 & -0.253 & -0.518 \\
\hline \multicolumn{9}{|l|}{ Proportion } \\
\hline total & & & & & & & & \\
\hline effect that is & 0.429 & 0.607 & 0.321 & 0.255 & 0.570 & 0.615 & 0.225 & 0.274 \\
\hline mediated & & & & & & & & \\
\hline
\end{tabular}

\section{Discussion}

Under the background of the new round of medical and health system reforms, the hospital structure and hospital strategy have been adjusted accordingly, resulting in changes in the original departments, the relationship between superiors and subordinates, and among colleagues, thereby breaking the original psychological contract of medical staff. Psychological contract violation is inevitable in organisations. The violation and imbalance of the psychological contract can lead to an increase in 
dissatisfaction among medical staff and trigger different behavioural responses. Physicians play a vital role in hospitals. Paying attention to changes in their behaviours and creating a better physician-hospital relationship is of great significance to the challenges of current society.

The medical field in China has unique characteristics. It is important to understand when employees are likely to interpret discrepancies as psychological contract violations and under what circumstances employees will respond strongly to such violations. This study found that when physicians perceive psychological contract violations, physicians' positive behaviours decrease and negative behaviours increase. These results support the findings of previous studies (Turnley \& Feldma, 1999; Bellou, 2009; Bunderson, 2001; Trybon, 2016, 2017)[14,2,4,35,3]. Bunderson (2001)[4] and Trybon (2016, 2017)[35,3] showed that psychological contract violation is positively related to physicians' turnover intention and a high level of fulfilment of their psychological contract provides more motivation to contribute to the mission statement. This results is consistent with social exchange theory (Adams, 1963; Blau, 1964)[43,44] and control theory (Carver \& Scheier, 1982)[45], when physicians feel that there is a difference between the content promised by the hospital and the content actually received, from the perspective of the physician, this difference reflects on an imbalance in the social exchange relationship between them and the organisation. Physicians have the motivation to eliminate or reduce this imbalance, including both positive and negative behaviours.

In addition, the actual response of physicians to psychological contract violation is likely to be strongly influenced by the context surrounding the psychological contract 
violation. By paying attention to the influence of organisational justice on physician's psychological contract violation and EVLN behaviour, this paper found a mediating effect of organisational justice. A high level of organisational justice has a negative buffering effect on psychological contract violations and physicians' exit and neglect behaviours, and a positive buffering effect between psychological contract violations and physicians' voice and loyalty behaviours; furthermore, its mediating effect is very significant. Trybon (2016)[35] also showed that organisational justice negatively affected physicians' intention to leave in Belgium. Pan Y. (2016)[46] believes that organisational justice plays a part in the intermediary role between nurses' psychological contract fulfilment and EVLN behaviour in China; Zhou P. (2019)[8] used Chinese public hospital physicians as research subjects and found that fair perception is an important intermediary for the fulfilment of hospital responsibilities and the resignation of physicians. These results are consistent with the notion that when people think that the decision-making process is fair, people's reactions to unfavourable behaviours are less severe (Brockner \& Wiesenfeld, 1996; Moorman, 1991; Skarlicki \& Folger, 1997)[47-49].

Previous scholars have recognised that the relationship between professional employees and their employing organisation is particular to the employment (Trice, 1993; Van Maanen \& Barely, 1982)[50,51], and the response of professional employees to perceptions that their organisation is not trying to fulfil the contract is also different (Bunderson, 2001; Trybon, 2016, 2017)[4,35,3]. In summary, physicians, also professional employees, interact with an employing organisation both as professionals and employees. So, establishing a good incentive mechanism for physicians requires attention to the role 
of psychological contract violation. Hu GP. (2013)[52] found that organisational justice is essential to the stability of professional employees. The results of this study also suggest that hospitals should pay attention to organisational justice factors in the development process of hospitals, and build a scientific and reasonable distribution system and evaluation system. The sense of organisational justice is the physician's perception of the fairness of the hospital. In addition to the perception of distribution results, it is important to pay attention to the distribution procedures before the results. Siun, Gallagher, Miles, \& Little. (2019)[53] suggest a supplementary procedure that positions commitment to the care and just treatment of participants as a foundation of any macroallocation procedure. Therefore, hospitals should develop the distribution system to ensure the openness and transparency of the distribution procedures so that physicians can participate in the formulation of the distribution system as much as possible, integrate the assessment system with the importance and complexity of the position which reflect physicians' own needs, self-worth, and sense of honour to ensure meeting the wishes of most staff. At the same time, a scientific and effective supervision system should be established to ensure fairness, promote positive behaviours of physicians, and reduce burnout and other negative behaviours, thereby reducing human resource management risks.

\section{Conclusion}

The results of this study demonstrate that physicians' psychological contract violation has a direct impact on physicians' EVLN behaviour, which has a positive effect on constructive behaviour and a negative effect on destructive behaviour. In addition, it 
suggests that organisational justice has a mediating effect between physicians' psychological contract violation and EVLN behaviour, which accounts for a large proportion of the total effect.

\section{Limitations and future research}

This study is not without its limitations, and its results should be interpreted carefully. First, this study is only a study of tertiary public hospitals in Beijing. We can consider factors such as different levels and different regions for further research, and consider physicians from multiple hospitals to draw more general conclusions. Second, the evolution of physicians' behaviours is a dynamic and long-term process. This article only conducted a cross-sectional survey and did not conduct dynamic tracking studies. In fact, the introduction of public hospital reform policies and the internal reforms of hospitals are more likely to cause changes in physicians' behaviours. It would be more meaningful to analyse the changes in physicians' behaviours before and after reforms to evaluate reform policies. Third, considering that it is difficult to obtain evaluation information from physicians by multiple parties, the effect indicators of this study mainly rely on individual self-evaluation. In the future, information may be collected through multiple channels and methods to ensure comprehensiveness and objectivity.

\section{Acknowledgments}

The authors would like to thank National Natural Science Foundation of China (no.71974133,

71573182) for providing financial support for this research undertaking and all subjects who participated in the study.

\section{Authors' contributions}


LJH was responsible for conceptualization, methodology, investigation, validation, formal analysis, data curation, writing-original draft preparation and visualization. JLZ was responsible for conceptualization, methodology, writing-review and editing and supervision. YZ, TC and YFJ was responsible for investigation.

\section{Funding}

The research is supported by the National Natural Science Foundation of China (no.71974133, $71573182)$.

\section{Availability of data and materials}

The datasets used and/or analysed during the current study are available from the corresponding author on reasonable request.

\section{Ethics approval}

The study was conducted according to the guidelines of the Declaration of Helsinki, and approved by the Ethics Committee of Capital Medical University (protocol code Z2020SY131, date 2020-11-16). We explained the contents of the investigation to all participants and insured they get informed consent.

\section{Consent for publication}

Not applicable.

\section{Competing interests}

The authors declare that they have no competing interests.

\section{References}

[1] Chenying Wang, Ji'anCheng (intern), Yukun Qi (intern). Practicing medicine in the cracks: $68.1 \%$ of the interviewed doctors bluntly said that the doctor's practice environment is poor . China Youth Daily. 2015. (in Chinese) 
[2] Victoria Bellou. Matching individuals and organizations: evidence from the Greek public sector[J]. Employee Relations. 2009;31(5).

[3] Trybou J , Gemmel P, Desmidt S, et al. Fulfillment of administrative and professional obligations of hospitals and mission motivation of physicians. BMC Health Services Research. 2017;17(1):28.

[4] Bunderson J S. How Work Ideologies Shape the Psychological Contracts of Professional Employees: Doctors' Responses to Perceived Breach. Journal of Organizational Behavior. 2001;22(7):717-741.

[5] Jeroen T, Canfyn S, Lieven A, et al. Physician-hospital exchanges and extra-role behaviour of physicians: The moderating role of the chief medical officer. International Journal of Healthcare Management. 2015.

[6] Zhang, M., et al. Coping and compromise: a qualitative study of how primary health care providers respond to health reform in China. Human Resources for Health. 2017;15(1):1-12.

[7] Zeyu Wu. Research on the relationship between doctors' psychological contract, organizational commitment and job satisfaction in public hospitals. Zhongnan University. 2013. (in Chinese)

[8] Pin Zhou, Jianwei Shi, Hongbo Zhu, et al. Research on the Association Mechanism and Moderating Variables between Physician's Perceived Hospital Accountability Status and Turnover Willingness. China Health Resources. 2019;22( 06):465-471+491. (in Chinese)

[9] Leineweber, C. , Peristera, P. , Bernhard-Oettel, C. , \& Eib, C. Is interpersonal justice related to group and organizational turnover? results from a swedish panel study. Social Science \& Medicine (1982). 2020.

[10] Rousseau D M. Psychological contract in organizations :Understanding written and unwritten agreements. Thousand Oaks . 1995;CA :Sages.

[11] Schein E H . Organizational Psychology. New Jersey: Prentice-Hall. 1980. 
[12] Rousseau, D.M. and McLean Parks, J.M. The contracts of individuals and organizations, Research in Organizational Behavior. 1993;15:1-43.

[13] Robinson M S L. When Employees Feel Betrayed: A Model of How Psychological Contract Violation Develops. The Academy of Management Review. 1997;22(1):226-256.

[14] Turnley W H. A Discrepancy Model of Psychological Contract Violations. Human Resource Management Review. 1999;9(3):367-386.

[15] Rousseau D.M. New hire perception of their own and their employer's obligations' study of psychological contracts. Journal of Organizational Behavior. 1990;11(5):389-400.

[16] Robinson S L , Kraatz M S , Rousseau D M. Changing Obligations and the Psychological Contract: A Longitudinal Study. Academy of Management Journal. 1994;37(1):137-152.

[17] Robinson M S L . When Employees Feel Betrayed: A Model of How Psychological Contract Violation Develops. The Academy of Management Review. 1997;22(1):226-256.

[18] Millward L J , Hopkins L J. Psychological Contracts, Organizational and Job Commitment. Journal of Applied Social Psychology. 1998;28(16):27.

[19] Lee, C , Tinsley, CH. Psychological normative contracts of work group member in the U.S. and Hong Kong. Working Paper. 1999.

[20] Jackie Coyle-Shapiro, Kessler I. Consequences Of The Psychological Contract For The Employment Relationship: A Large Scale Survey. Journal of Management Studies. 2000;37(7):28.

[21] Hanson R A. Exit, Voice, and Loyalty: Response to Decline in Firms, Organizations, and States. By Hirschman, Albert O. (Cambridge: Harvard University Press, 1970. Pp. 162. \$6.95.). American Political Science Review. 1970;64(4):1274-1276.

[22] Dan F. Exit, Voice, Loyalty, and Neglect as Responses to Job Dissatisfaction: A Multidimensional 
Scaling Study. Academy of Management Journal. 1983;26(4):596-607.

[23] Hagedoorn M, Buunk B P , Vliert E V D. Opening the Black Box Between Justice and Reactions to Unfavorable Outcomes in the Workplace. Social Justice. 1998; 11(1):41-57.

[24] Lepine D J A. Helping and Voice Extra-Role Behaviors: Evidence of Construct and Predictive Validity. The Academy of Management Journal. 1998;41(1):108-119.

[25] Mariët Hagedoorn, Yperen N W V , Vliert E V D , et al. Employees' reactions to problematic events: A circumplex structure of five categories of responses, and the role of job satisfaction. Journal of Organizational Behavior. 1999;20(3):309-321.

[26] Liljegren M, Nordlund A, Ekberg K. Psychometric Evaluation and Further Validation of the Hagedoorn et al. Modified EVLN Measure. Scandinavian Journal of Psychology. 2008;49(2):169-177.

[27] Greenberg J. A Taxonomy of Organizational Justice Theories. The Academy of Management Review. 1987;12(1).

[28] J.Adams.Inequality in Social Exchange. Experimental Social Psychology. 1965; 266-267.

[29] Thibaut,J.Walker,L. Procedural justice: A psychological analysis. Hillsdale, NJ.:Lawrence Erlbaum Associates. 1975.

[30] RJ. Bies, J, F, Moag. Interactional justice: Communication criteria of fairness. Research on Negotiations in Organizations.Greenwich. CT: JAIPress. 1986.

[31] J. Green berg. Organizational justice; Yesterday, today, and tomorrow. Journal of Management. 1990;16 (2): 399-432 .

[32] Feng Wei. Research on Organization-Manager Psychological Contract Violation. Fudan University. 2004(in Chinese) 
[33] Chatman, J.A. Improving interactional organizational research: a model of person-organization fit, Academy of Management Review. 1989;14: 333-49.

[34] Griffeth, R.W., Hom, P.W. and Gaertner, S. A meta-analysis of antecedents and correlates of employee turnover: update, moderator tests and research implications for the next millennium, Journal of Management. 2000;26: 463-88.

[35] Trybou J , Gemmel P, Annemans L. The impact of economic and noneconomic exchange on physicians' organizational attitudes: The moderating effects of the Chief Medical Officer. Health Care Management Review. 2016;41(1):75.

[36] Hair J F , Black W C , Babin B J , et al. Multivariate Data Analysis: A Global Perspective. 2010.

[37] Rusbult C E , Farrell D , Iii R A G M. Impact of Exchange Variables on Exit, Voice, Loyalty, and Neglect: An Integrative Model of Responses to Declining Job Satisfaction. The Academy of Management Journal. 1988;31(3):599-627.

[38] Colquitt J A, Conlon D E, Wesson M J , et al. Justice at the millennium: a meta-analytic review of 25 years of organizational justice research. Journal of Applied Psychology. 2001;86(3):425-45.

[39] Sobel ME. Asymptotic Confidence Intervals for Indirect Effects in Structural Equation Models: Sociological Methodology. 1982;13(13): 290-312.

[40] Haynes S N , Richard D C S , Kubany E S. Content Validity in Psychological Assessment: A Functional Approach to Concepts and Methods. Psychological Assessment. 1995;7(3):238-247.

[41] Holden R J , Karsh B T. The technology acceptance model: its past and its future in health care. Journal of Biomedical Informatics. 2010;43( 1):159-172.

[42] Fornell C , Larcker D F. The use of canonical correlation analysis in accounting research. Journal of Business Finance \& Accounting. 2010;7(3):455-474. 
[43] Adams J S. Toward an Understanding of Inequity. Journal of Abnormal \& Social Psychology. $1963 ; 67(5): 422-436$.

[44] Blau, P. M. Exchange and power in social life. New York: Wiley. 1964.

[45] Carver, C. S., \& Scheier, M. F. Control theory: A useful conceptual framework for personality-social, clinical, and health psychology. Psychological Bulletin. 1982;92: 111-135.

[46] Yan Pan. An empirical study on the relationship between nurses' psychological contract and their EVLN behavior. Zhejiang University of Traditional Chinese Medicine. 2016.(in Chinese)

[47] Brockner J, Wiesenfeld B M. An integrative framework for explaining reactions to decisions: interactive effects of outcomes and procedures. Psychological Bulletin. 1996;120(2):189-208.

[48] Moorman R H. Relationship Between Organizational Justice and Organizational Citizenship Behaviors: Do Fairness Perceptions Influence Employee Citizenship?. Journal of Applied Psychology. 1991;76(6):845-855.

[49] Skarlicki D P , Folger R. Retaliation in the workplace: The roles of distributive, procedural, and interactional justice. Journal of Applied Psychology. 1997;82(3):734-443.

[50] T. E P. Occupational Subcultures in the Workplace (Book). Arbitration Journal. 1993.

[51] Maanen J V , Barley S R. Occupational Communities: Culture and Control in Organizations. Research in Organizational Behavior. 1982;6(29):130.

[52] Guoping Hu. Research on the relationship between organizational justice and turnover intention of knowledge-based employees in B company. Shanghai: East China University of Science and Technology. 2013.(in Chinese)

[53] Siun, Gallagher, Miles, \& Little. Procedural justice and the individual participant in priority setting: doctors' experiences. Social science \& medicine (1982). 2019. 
Figures

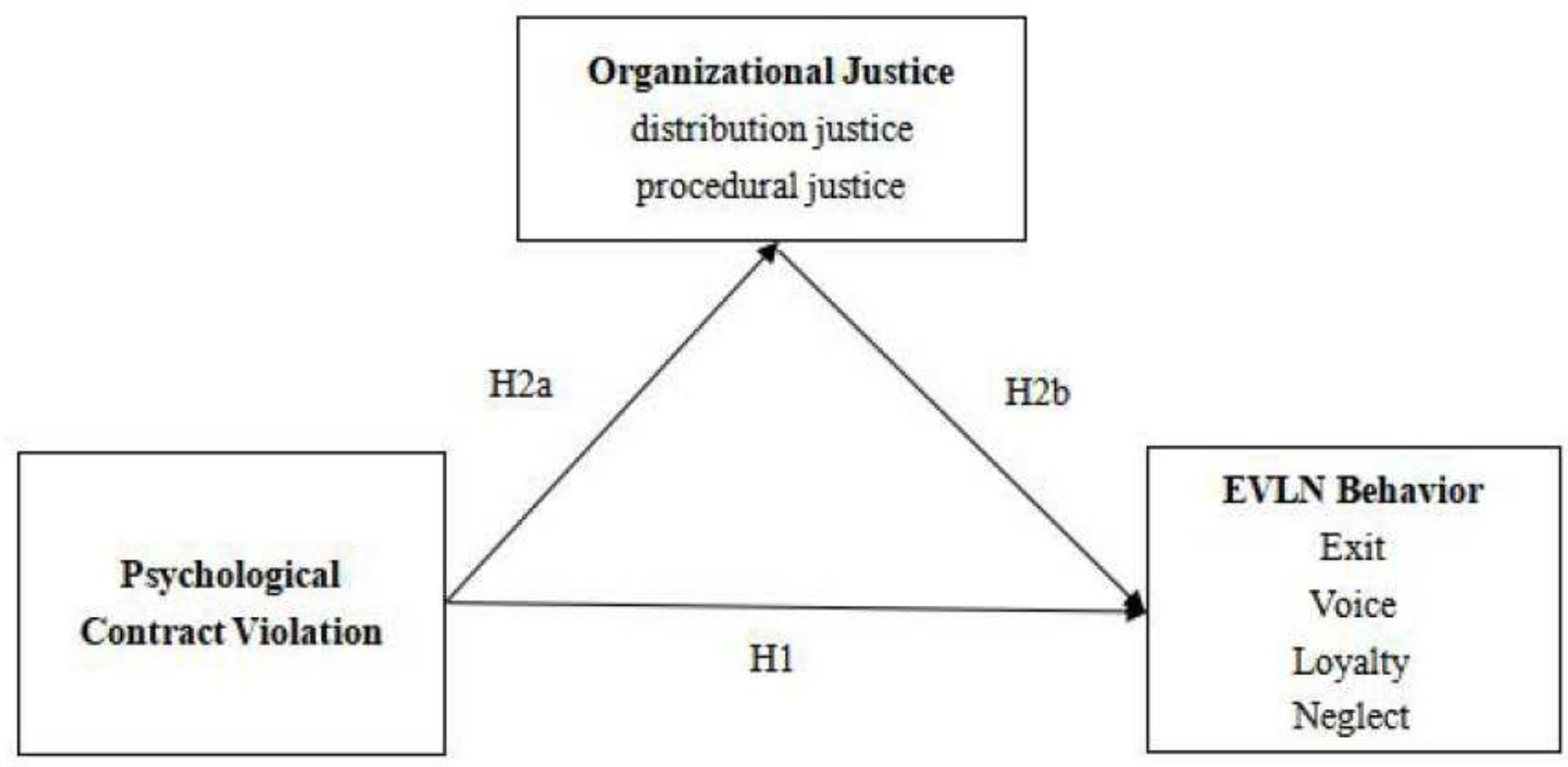

Figure 1

Study Framework 